\title{
Applications of physical methods in estimation of soil biota and soil organic matter
}

\author{
Chagovetc Sergei ${ }^{1,2}$, Shenglei $\mathrm{Fu}^{1,2}$,* \\ 1 Key Laboratory of Geospatial Technology for the Middle and Lower Yellow River Regions, Ministry of Education, College of Environment \\ and Planning, Henan University, Kaifeng 475004, China \\ 2 Henan Key Laboratory of Integrated Air Pollution Control and Ecological Security, Henan University, Kaifeng 475004, China
}

\section{ARTICLE INFO}

\section{Article history:}

Received January 21, 2020

Revised March 24, 2020

Accepted April 27, 2020

\section{Keywords:}

Soil organic matter

Soil biota

Advanced method

Acoustic method

Spectroscopy

Tagging

\begin{abstract}
A B S T R A C T
Soil biota is the living component of soil organic matter (SOM), and plays a key role in the decomposition of SOM. Both soil biota and SOM are indicators of soil fertility and soil quality. However, they both are sensitive to soil disturbance. Although researchers developed various technologies to detect soil biota and SOM, they are mostly destructive and cause disturbance to soil, which may not reflect the actual situation of soil biota and SOM. Therefore, here we mostly focused on the non-destructive physical methods for estimating soil biota and SOM and discussed their advantages and disadvantages. These methods include but not limited to acoustic detection, radio frequency identification, radioactive tagging, hyperspectral sensing and electron energy loss spectroscopy. In addition, we pointed out the current research problems and the potential research directions for applications of physical methods in estimation of soil biota and SOM.
\end{abstract}

(c) Higher Education Press 2020

\section{Introduction}

Soil biota plays a central role in biogeochemical processes in soil (Coleman et al., 2016). The diversity and abundance of soil biota could indicate the status of soil health (Hodkinson and Jackson, 2005). However, soil biota is mostly hidden from our direct observations due to the small sizes, so scientists usually detect the "markers" left by soil biota rather than biotic groups themselves. These markers can be presented as excretes, tunnels or sounds (Harrison et al., 1993; Njoroge et al., 2017). Soil biota is the living component of soil organic matter (SOM), but they both are indicators of soil fertility and soil quality (Bongers and Ferris, 1999). For this reason, we attempt to cover the estimation methods for both soil biota and $\mathrm{SOM}$ in this article due to their inextricable relations. There are

\footnotetext{
* Corresponding author

E-mail address: fsI@vip.henu.edu.cn (S. Fu)
}

many methods of estimating soil biota and SOM. The methods can be divided into two big groups: classical and advanced. Classical methods include chemical, biochemical and molecular analysis, and they are commonly used after destructive sampling; the advanced methods are more physically oriented and usually non-destructive.

For soil microorganisms and SOM measurement, chemical, biochemical and molecular methods are normally used (Skinner et al., 1952; James, 1958; Taylor, 1962; Foster and Rovira, 1976; Chen et al., 2001; Sogin et al., 2006; Lahaye et al., 2008). These methods are normally complicated and require pretreatment with plenty of reagents. Besides, they are destructive and non-repetitive because soil samples are taken from the field and brought back to laboratory. In other words, it lacks the possibility to analyze the same sample by different methods at the same time or by the same method at different times. The repetitiveness can be approximately achieved through the simultaneous analysis of several samples from nearby locations. The optimum time required 
for biological analysis is about two days, but it usually takes about a couple of weeks or more. Due to these limitations classical methods may underestimate the soil biota and SOM.

For soil fauna such as earthworms, ants and termites, it is possible to use hand-sorting method in all soils, however it is very labor intensive and time consuming (Schmidt, 2001a). Additionally, this method requires some destructive extraction technique like excavation, washing and sieving (Raw, 1960) or behavioral extraction (heat, electrical, chemical) (Raw, 1959; Tisdall and McKenzie, 1999; Schmidt, 2001b; Lawrence and Bowers, 2002), which inevitably lead to underestimation of the real abundance of animals due to the fact that animals may move into deeper soil instead of crawling to the soil surface. Moreover, destructive extraction means that the habitat is destroyed, so such methods cannot be considered as environmental friendly.

Swift development of physics provides us with various methods to measure soil biota and SOM. Physical methods are usually used to provide information about soil biota based on physical properties such as temperature, moisture, shape, size, sound or compressibility, and physical methods also have been applied in exploring movement patterns or spatial distribution of soil animals (Joyner and Harmon, 1961; Mankin et al., 2000; Brandhorst-Hubbard et al., 2001; Bastardie et al., 2003). A number of physical methods can provide information about SOM based on mass weight of chemical elements but usually heavy or radioactive elements, while main organic elements are light and non-radioactive. If a physical method is able to detect light element, it will provide not only information about organic elements but also additional information about dopants, contaminants or environment of the sample in one experiment.

Moreover, physical methods do not usually require long and complex pretreatment. Most of them are non-destructive allowing further investigation by other methods or repeating the same experiment in situ. Therefore, there is a great potential in application of physical methods in studying soil biota and SOM.

\section{Applications of physical methods in soil biota estimation}

\subsection{Acoustic detection}

Acoustic detection method is used to conduct quantitative and qualitative analysis of earthworms and larger invertebrates in situ (Mankin et al., 1998; Mankin et al., 2000; BrandhorstHubbard et al., 2001; Njoroge et al., 2017, 2018). For this method, a microphone is installed into the ground to record sounds produced by the soil biota while moving, feeding, etc. Recorded sounds are processed with noise reduction and compared with laboratory prerecorded samples to estimate the types and numbers of soil invertebrates.

This non-destructive method can be used for soil mapping of populations. The method is used to study insects and other soil animals which are able to make sounds. In several studies the sounds were used as an indicator of life (Njoroge et al., 2017 , 2018). Simultaneous measurements of acoustical activity and oxygen level allowed to trace a mortality rate in hermetic storages. Figure 1 represents correlations between oxygen consumption and sound pulse rates of insects. Acoustic detection made it possible to estimate the duration required for reduction of insect activity to levels which inflict negligible damage. However, it shows that the sound generated by small numbers of insects may be under the threshold level, so real presence or absence of insects may be underestimated by the method.

In addition, acoustic method is able to map soil insect populations without labor intensive techniques such as destructive digging (Mankin et al., 2000; Brandhorst-Hubbard et al., 2001). The correlation between sound pulse rates and the number of different soil invertebrates was reported. First, the sound pulse rates were recorded, then the number of soil species were counted by excavation of soil cores from each sample point on either side of the microphone slit. In most cases the intensity of sounds matches with the density of soil species making it possible to map soil populations. However, different species produce different sound levels, and interaction between species like predation could obscure the identification.

The recording requires quiet conditions, while wind, vehicles and other sound producers cause high noise level and limit usable places for the method. However, it was reported there were no suitable systems of noise reduction systems for a pre-record noise subtraction, but only afterrecord noise reduction (Mankin et al., 1997; Mankin et al., 2000). Pre-record noise subtraction will allow faster and more accurate analysis in almost any conditions, but it may increase an overall cost of equipment as it requires additional equipment. Unfortunately, the method is suffering from several problems, such as the dependence of the detection radius on the soil structure (usually $10-30 \mathrm{~cm}$ ) and nondistinguishable types of invertebrates due to similarity of sounds they made. The identification of species sound requires audition of recordings by specially trained personnel, so the method is still time-consuming as discerning of records requires time and skills. Hopefully, with the development of computers and artificial intelligence such as neural networks, the audition can become automated.

\subsection{Radio frequency identification and radioactive tagging}

Tagging is a method of tracking soil animals to track their movement patterns. After attaching a special tag to the animal, it is returned to the soil and tracked down by a special detector. There are several types of tags and detectors such as radio frequency identification (RFID) and radioactive tags (Joyner and Harmon, 1961; Bastardie et al., 2003; Scheibler et al., 2014).

RFID tags are subdivided into two groups: active and passive tags. Active tags contain an internal battery to provide communication with detector over great range, but it is usually a trade-off between signal power, lifetime and battery size, 

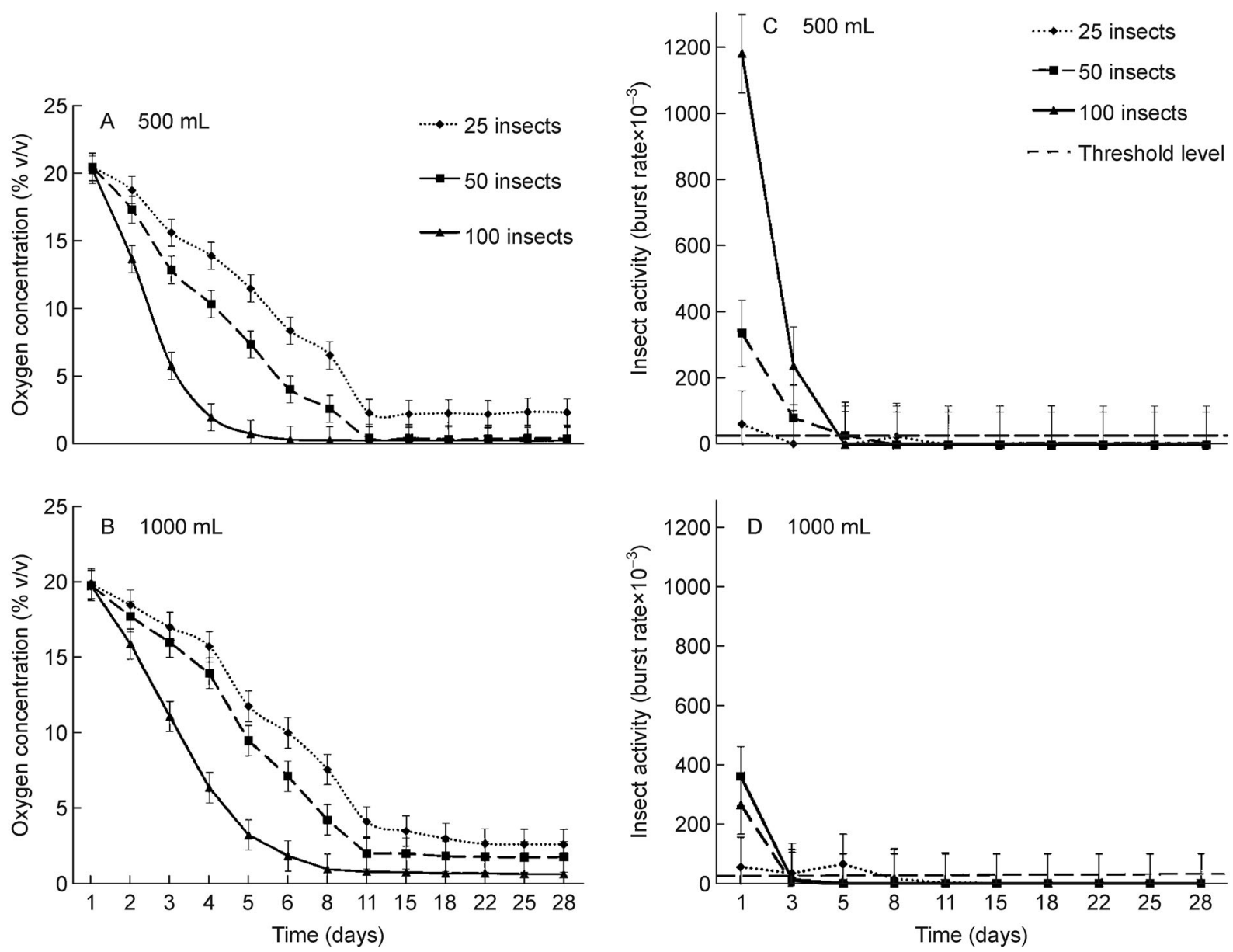

Fig. 1 Oxygen consumption patterns for 25, 50, and 100 Sitophilus oryzae adults enclosed in hermetically sealed (A) 500-mL jars and (B) 1000-mL jars (left) and rates of sound bursts from 25, 50, and $100 \mathrm{~S}$. oryzae adults enclosed in hermetically sealed (C) 500-mL jars and (D) 1000-mL jars (right) (Njoroge et al., 2017).

additionally limited by animal size. Passive tags work identically to anti-theft tags in shops, they have unlimited endurance, however the range of detection is extremely limited (up to a few meters at most). It can be used for monitoring animal movements in limited spaces like ecological corridors, for example, animals living in burrows like hamsters (Scheibler et al., 2014).

However, as it was said before, signals are relatively weak and can be attenuated or blocked over short ranges by certain materials (Bauer-Reich et al., 2014). The read distance is dropped as moisture levels increased. For all types of tags read distance is declined with the depth of burying, but different dependencies exist. Some tags are good near to the soil surface, but rapidly lose their signal with increasing soil depth, while others have more linear (no rapid falls) or even hyperbolic dependency (on the specific depth the fall of signal becomes smoother).

Also, currently there is no standard for this technology, which causes the incompatibility of tags and readers in some cases. Generally, the transmitter weights no more than five percent of the animal's bodyweight to reduce effects on the animal's behavior and quality of life (Wheater et al., 2011). It should be noted that soil animals are smaller than surface or underwater species, so tags need to be smaller than usual, coupled with the fact that external tags may be easily lost by friction. Therefore, tags are required to be small, nonseparable or at least difficult to separate from the soil animal. Besides, they should generate signals powerful enough to be detected at the required depth.

The radioactive tagging method uses radioactive isotopes. The detector used is any type of the radiation detector. The method allows 3D measurement of soil biota moving (Joyner and Harmon, 1961; Bastardie et al., 2003). Figure 2 shows the burrow systems of earthworms. Earthworms were tracked in artificial soil cores, two circles represent the top and the bottom of the soil core. Digging was not continuous, it was interrupted by inactivity phases, each letter labels the beginning of a digging event in alphabetical order. During inactivity phases earthworms moved inside the tunnels, the type of each line indicates the number of crossings per segment, solid line: > 80; dashed line: 40-79; dotted line: 0 40. Nonetheless, the application of the method in situ may be 

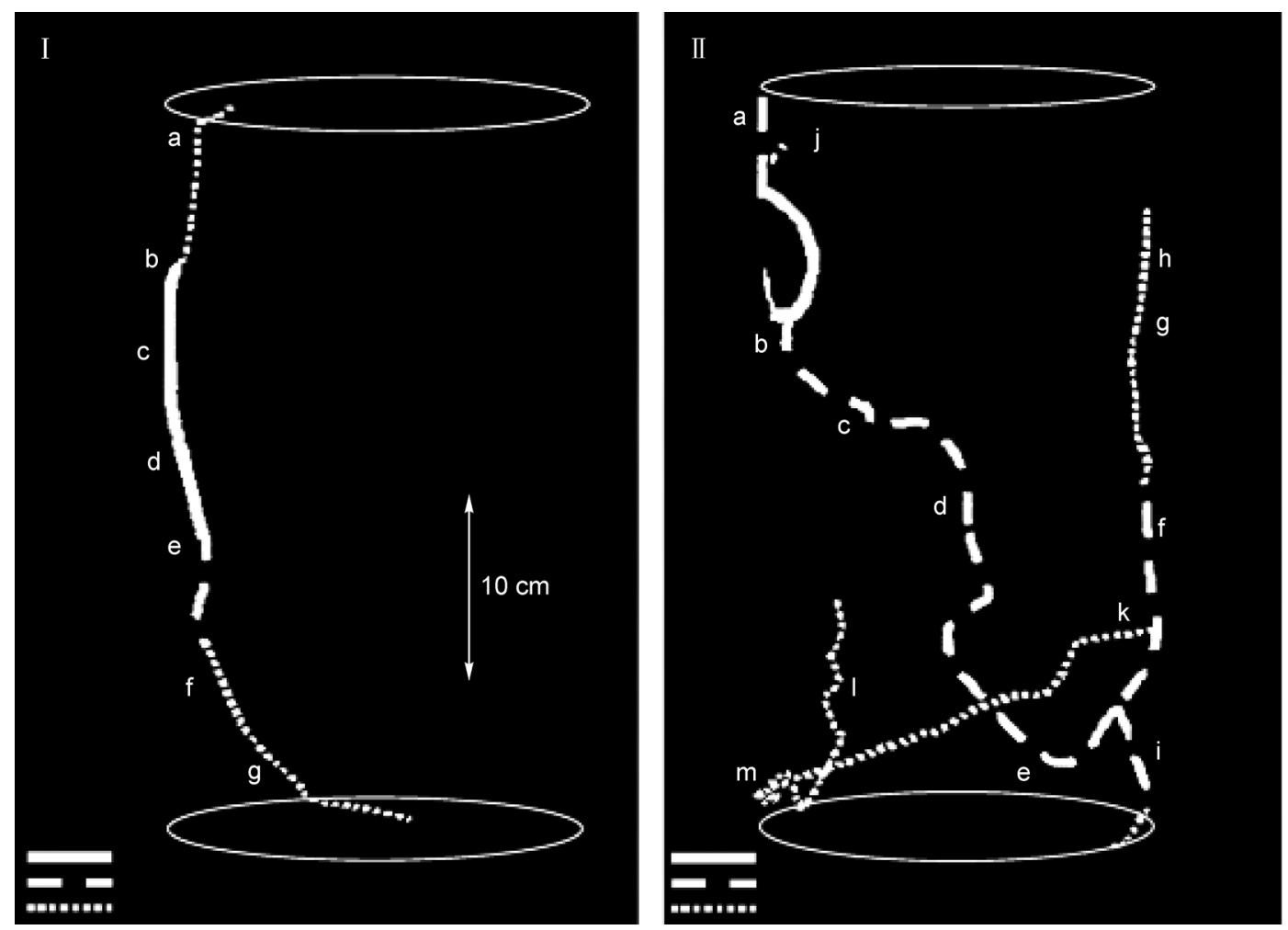

Fig. 2 The 3D representation of trajectories for the burrow systems of two types of earthworms (Bastardie et al., 2003).

limited by the possibility of predation and the presence of radioactive elements in the soil, as they may create artifacts.

\subsection{Radiography}

Radiography (or X-ray attenuation or X-ray imaging) is used to make a photograph called "radiograph" of the soil by X-ray beams. It is similar to medical usage of X-rays. Denser area is darker on the photograph, the radioactive isotopes are brighter than others. The method requires the sample to be thin enough and soil animal species should be of different density from the soil. It is possible to simulate animal movement in the soil without large modification of their movement pattern with radiography. Other types of biomedical imaging, such as magnetic resonance imaging, may have similar applications. X-ray computed tomography is already in use for a long time although they are very costly (Harrison et al., 1993).

It was reported that radiography was used for quantifying movements of invertebrates in presence of insecticides (Zhu et al., 2013). It was detected that insecticide such as imidacloprid is not detected or evaded by larvae of the European chafer, Amphimallon majale, but movement of larvae was arrested after contact with concentrations of $\geqslant 0.6$ ppm of insecticide. X-ray radiography was also used for detection of fungal infection in wheat (Narvankar et al., 2009). Fungal infection in wheat kernels leads to changes in the density of the kernels. By comparing X-ray images of healthy and infected grains, it is possible to detect this density change. Same technique can be used for investigation of soil fungi.

\section{Applications of physical methods in soil organic matter estimation}

\subsection{Hyperspectral sensors}

Hyperspectral sensors collect information as a set of 'images'. Each image represents a narrow wavelength range of the electromagnetic spectrum, also known as a spectral band. These 'images' are combined to form a 3D hyperspectral data cube for processing and analysis. The operator needs no prior knowledge of the sample as an entire spectrum of electromagnetic waves is acquired at each point. Postprocessing allows all available information from the data set to be mined. The spatial relationships among the different spectra in a neighborhood allows more elaboration of spectral-spatial models for a more accurate segmentation and classification of the image. For more specific mathematical and physical information about the method of organic matter estimation with hyperspectral imaging, readers may refer to the report by Wang et al. (2018).

It was reported that hyperspectral imaging allowed to study a post-fire soil surface and to determine the surface cover types, however it is mentioned that hyperspectral sensors have high cost, but provide more detailed maps (Kokaly et al., 
2007). Figure 3 represents hyperspectral imaging of post-fire land. Obviously, different types of surface are capable to be detected, and it is also possible to represent subsurface soil or roots, so hyperspectral imaging can be used for plant root phenotyping or estimating root biomass (Bodner et al., 2018; $\mathrm{Li}$ and Guo, 2018). In addition, hyperspectral imaging was used for finding insects in crops (Singh et al., 2010; Haff et al., 2013). It has shown a high accuracy of detecting invertebrates with hyperspectral imaging.

Techniques involved in all these studies may help with searching of invertebrates in the soil. Unfortunately, the resolution of hyperspectral images is not really high and it takes time to create a hyperspectral cube, but it has less requirements to the soil properties compared to other spectral methods. On the other hand, significant data storage capacity is necessary since $3 D$ hyperspectral cubes are large and multidimensional data sets, usually exceeds hundreds of megabytes.

\subsection{X-ray photoelectron spectroscopy}

X-ray photoelectron spectroscopy (XPS) is a technique that

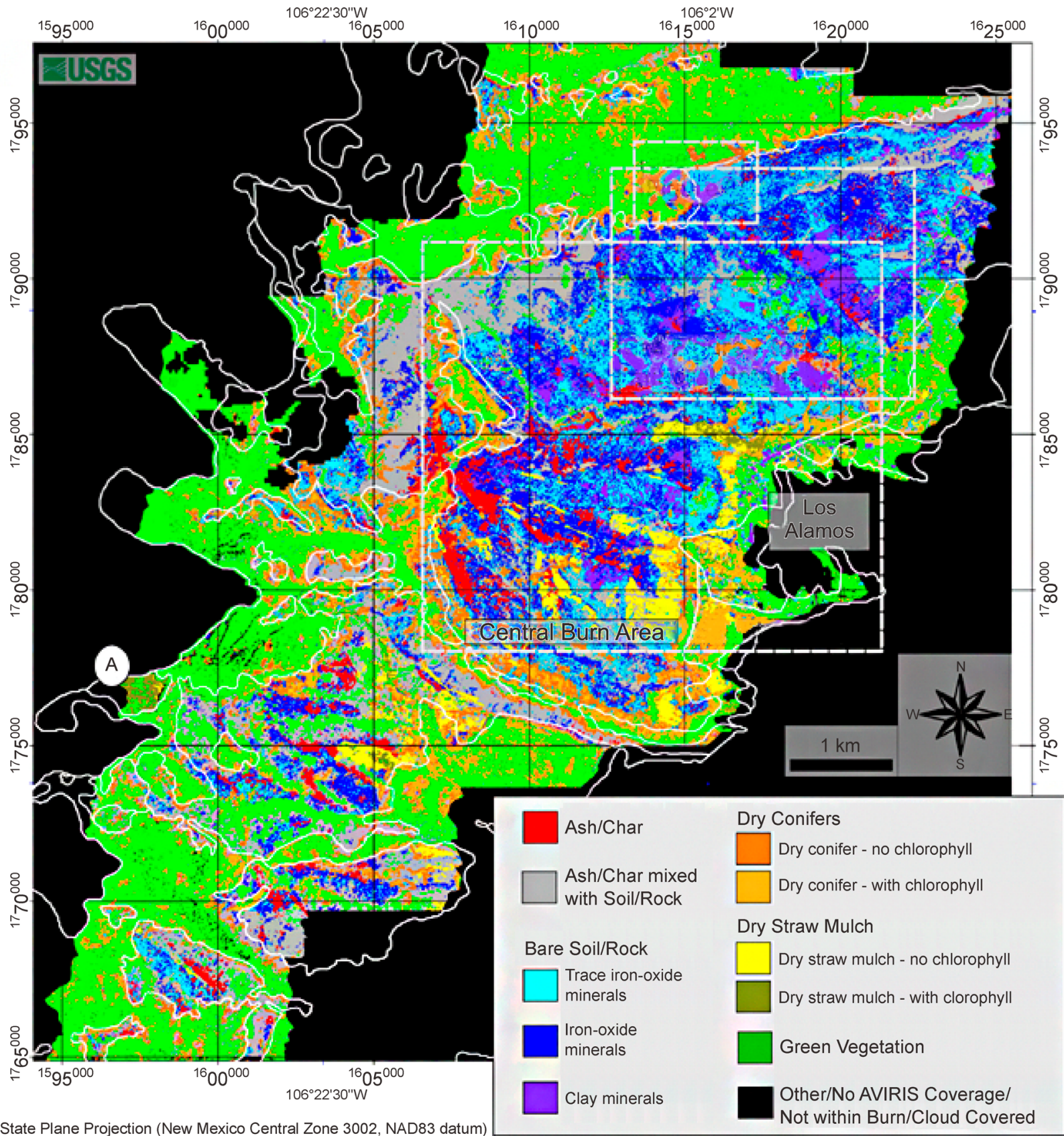

Fig. 3 AVIRIS-derived map of surface materials on the post-fire landscape at the Cerro Grande Fire, New Mexico (modified from Kokaly et al., 2007). 
investigates the elemental composition in a surface sample (up to $10-12 \mathrm{~nm}$ ). Spectra are obtained by measuring the number of electrons escaped the sample and their kinetic energy after irradiating it with X-rays. XPS detects all elements except hydrogen or helium, so it is possible to study organic compounds with different dopants or samples with their environment without any information lost. For most of the elements detection limits are in the parts per thousand, however it is possible to detect in limits of parts per million, but this requires special conditions (long collection time or only top surface study).

XPS was used to study methane and perchlorates formation in conditions close to Martian (Civiš et al., 2018). Recent discovery of methane on Mars has attracted an attention, as it may indicate some possible life forms on Mars. However, due to experiment limitations only methane formation was confirmed by XPS. Figure 4 illustrates photo-initiated formation of perchlorate in Martian soils with the small portions of chloride and anatase, which means that perchlorates were formed on Mars abiotically.

Another application of the method is studying black carbon (after-burn carbon forms) stability in the soils (Cheng et al., 2006; Liang et al., 2008). In both studies black carbon decomposition started on the surface of particles, while inlying material is protected by external part. Such resistance to decomposition leads to a lower microbial activity and lower $\mathrm{C}$ quality in the soil.

It is noteworthy that the method requires high vacuum, may cause degradation of some materials during analysis. Moreover, the largest study area is $1-5 \mathrm{~mm}^{2}$, making it suitable for micro- and nano-analysis, but not for bulk analysis. Nevertheless, it is possible to study elements that contaminate the surface, chemical or electronic state of each element in the surface, uniformity of elemental composition across the top surface and elemental composition of the surface. In short,

XPS spectra of the solid phase of our samples

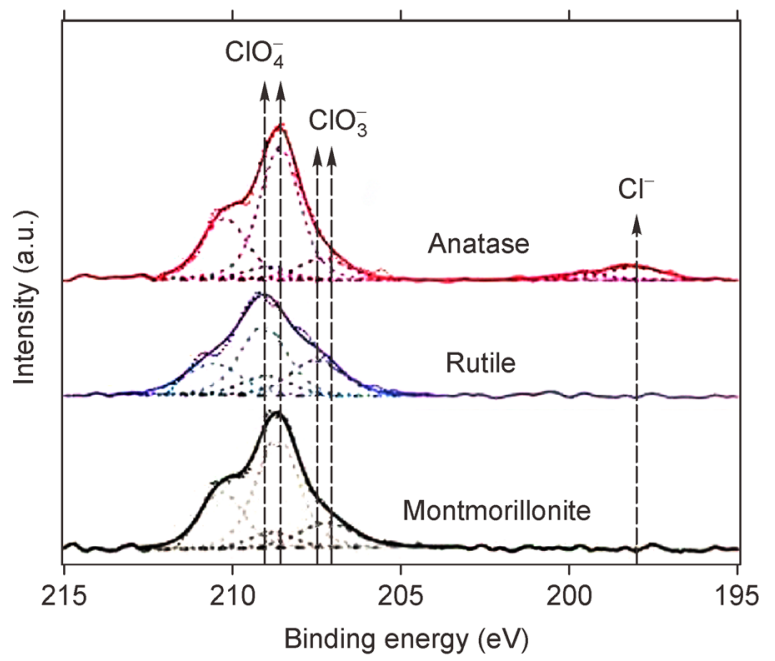

XPS is a non-destructive method for measuring the surface chemistry of almost any materials.

\subsection{Energy-dispersive X-ray spectroscopy}

Energy-dispersive X-ray spectroscopy (EDX or EDS) is a method of elemental analysis. Atoms of the sample are exited with beam of electrons or X-rays and emit a characteristic $X$ ray radiation. The method is often used with scanning electron microscopy and transmission electron microscopy, to study both microstructure and elemental composition. However, EDX requires high vacuum in the microscope. Hydrogen and helium have no characteristic X-ray emission, other light elements from lithium to neon can be detected by EDX, but their emission is strongly absorbed by the material and is occurred with the participation of valence electron influencing position and form of characteristic profiles on the specter.

One of the possible approaches is to analyze the elemental content of contaminants in carbon nanofibers and nanotubes production (Birch et al., 2011). It was reported that the metals found in samples could not be detected by commonly used methods. Another application of EDX is investigating the association between $\mathrm{Ca}$ and $\mathrm{C}$ and its contribution to the accumulation of organic carbon in a long-term experiment under a no-till system (Briedis et al., 2012). It was concluded that $\mathrm{C}$ bonding in the clay fraction was favored by the presence of $\mathrm{Ca}$.

Same as for XPS it is possible to analyze elemental composition of black carbon (Brodowski et al., 2005). It was reported that interior section of particles consisted of mostly carbon, while exterior surfaces were characterized by high amounts of oxygen and other elements, so it confirms the information from XPS section of this article. This result is illustrated on Fig. 5. The interior parts are characterized by high $\mathrm{C}$ content, while $\mathrm{O}$ content is rising from interior to

XPS standards of perchlorate, chlorate and chloride

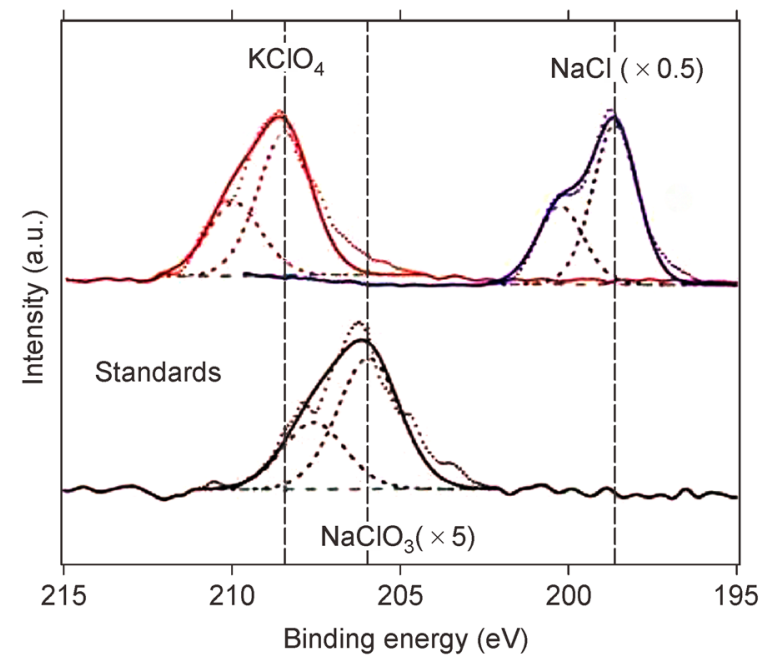

Fig. 4 XPS spectra in the region of $\mathrm{Cl} 2 \mathrm{p}$ of the catalysts after $3500 \mathrm{~h}$ of irradiation (Civiš et al., 2018). 

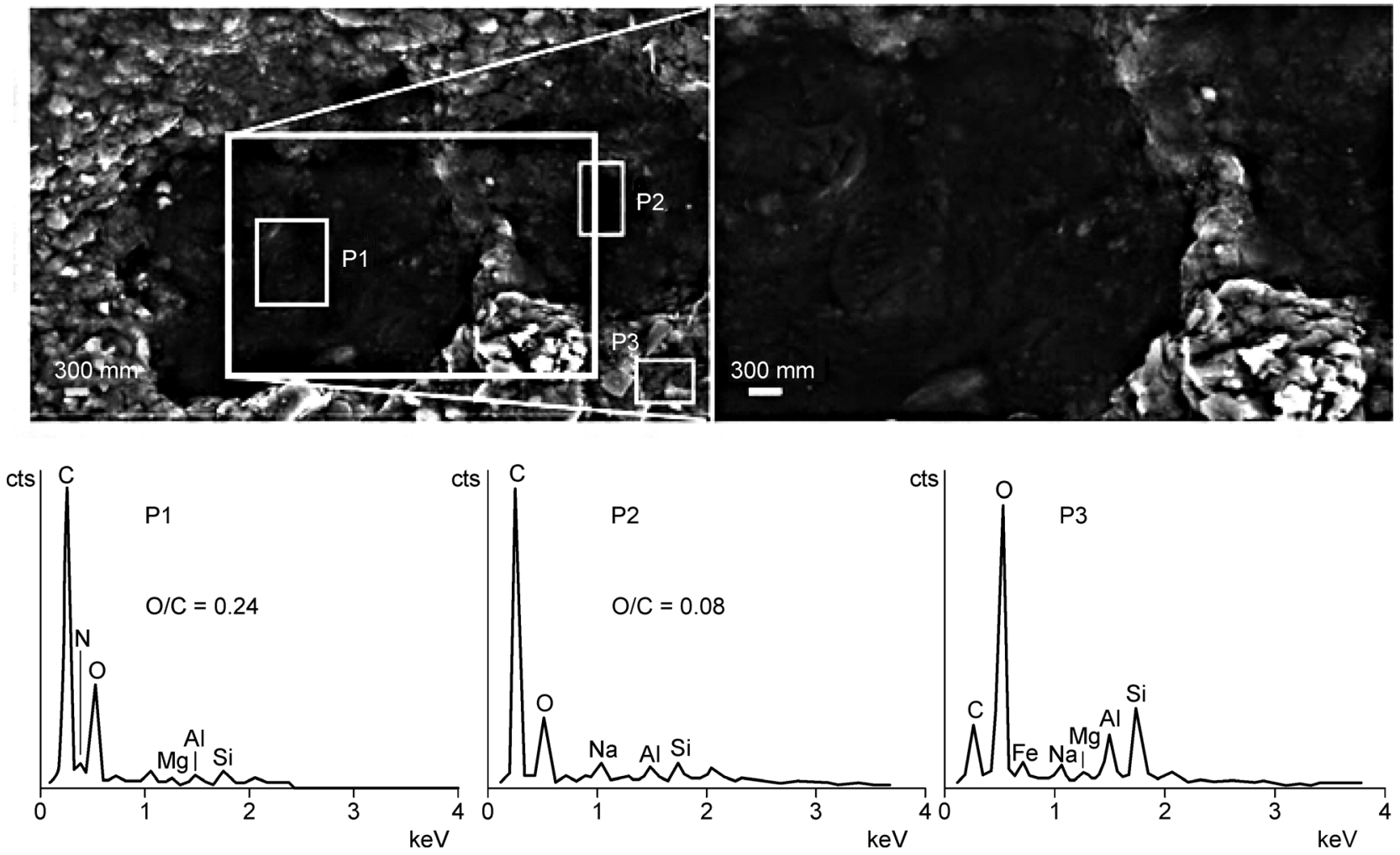

Fig. 5 Scanning electron micrographs and EDX spectrograms of an amorphous black carbon particle found in the density fraction of $<2.0 \mathrm{~g} \mathrm{~cm}^{-3}$ (cts $=$ counts) (Brodowski et al., 2005).

exterior parts. Other elements presented in particles may help to estimate the source of ashes.

\subsection{Electron energy loss spectroscopy}

Electron energy loss spectroscopy (EELS) is a complimentary technique to EDX. In EELS the material is radiated by narrow energy range electrons to study energy losses of inelastic scattered electrons. It works best with low atomic numbers and has a possibility to determine different form of the same element, however EELS is more difficult method than EDX. EELS inclines to work best at relatively low atomic numbers and works best with the elements ranging from carbon through the $3 \mathrm{D}$ transition metals. One of the strongest advantages of EELS over EDX is the ability to differentiate oxidation states of the same element. Additionally, there is scanning confocal electron energy loss microscopy, that allows imaging of nanomaterials.

EELS is rarely used for organic matter investigations, but it can provide a quantitative analysis at the nanometer scale of light elements (carbon, nitrogen, oxygen) and of other important elements such as iron, calcium, phosphorus, and sulfur (Jung et al., 2005). Figure 6 presents the evolution of EELS spectra of freeze-dried humic material remaining in the supernatant after settling. It was reported that EELS was used to study sulfur and nitrogen content in Syagrus coronate (palm tree), however no nitrogen content was found (Lins et al.,
2002). Also, organic matter chemical content of the carbonaceous chondrite meteorites was investigated (Garvie and Buseck, 2006). EELS showed presence of $\mathrm{N}$ and $\mathrm{S}$ dopants and high degrees of aromaticity of samples. It is alleged that amorphous carbon is the closest form to the sample carbon, however the presented differences show that other forms of carbon are also included in studied meteorites.

\subsection{Infrared, near-infrared and Fourier transform spectroscopy}

Infrared and near-infrared spectroscopy (IR and NIR) and Fourier transform infrared spectroscopy (FTIR) measures the intensity of light passed through the sample. The infrared light passed through material excites molecules or their parts and makes them oscillating, so when the energies of oscillation and energies of exciting is matched the light is absorbed. These peaks of absorption are characteristic and used to analyze the chemical composition of the sample. IR, NIR and FTIR are fast non-destructive techniques that only require limited sample preparation. In addition, several properties can be determined from a single scan. These methods also may be used to accurately measure solutions, pigments and greenhouse gases and they are portable enough to be used in field trials.

NIR was used to investigate soil mapping problem of precision agriculture in a farm (Wetterlind et al., 2010). The authors used only 25 calibration samples to predict soil 

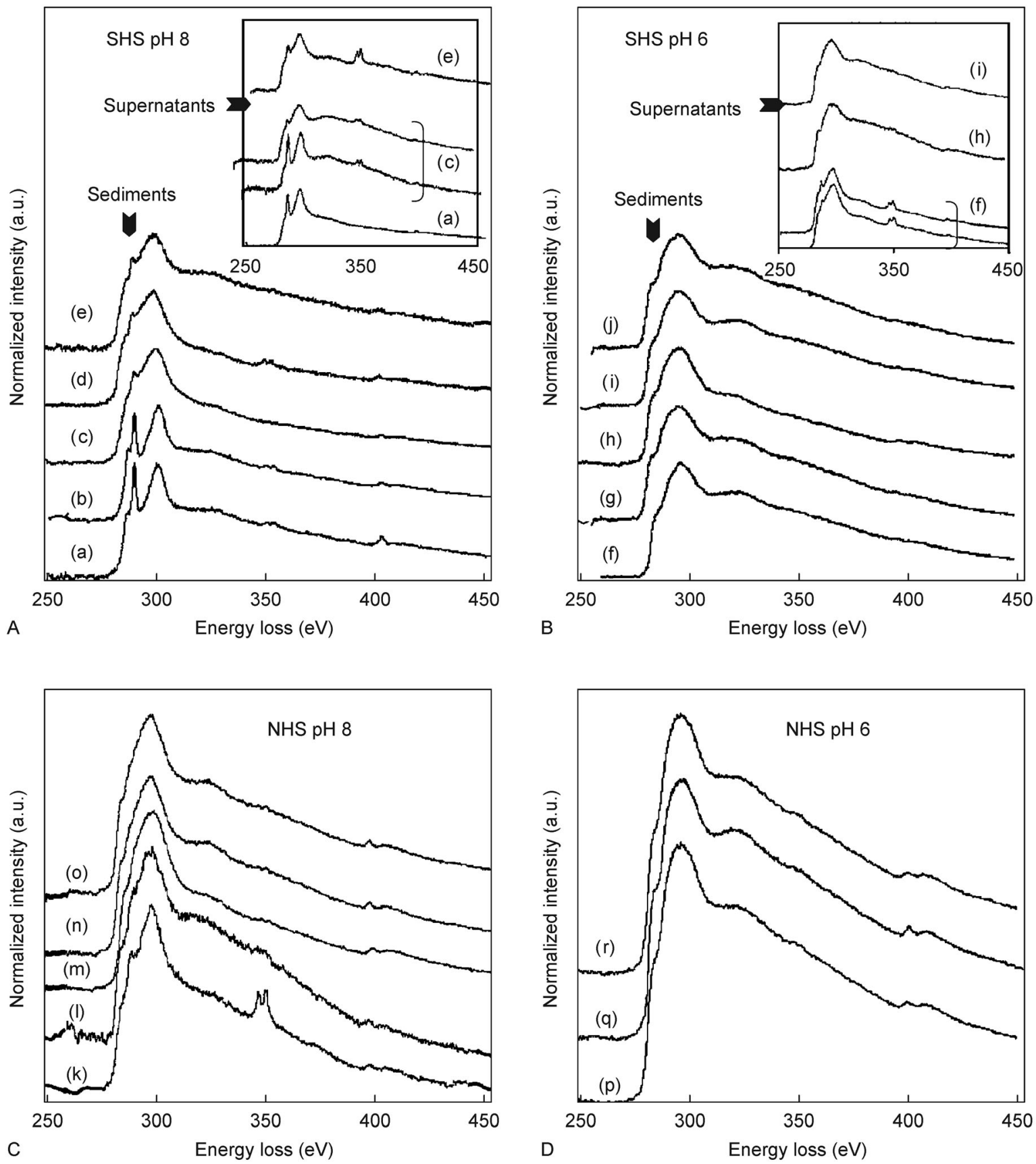

Fig. 6 EEL spectra of freeze-dried coagulated humic substances as a function of iron concentration: (A) and (B) synthetic humic substances(SHS) at pH 8 and 6, (C) and (D) natural humic substances(NHS) at pH 8 and 6 (Jung et al., 2005).

properties with good accuracy, however they noted that such number of samples could be too few. NIR can identify soil fauna species, such as nematodes, termites, and earthworms and their influence on environment. It was reported that the abundances of total nematode community and most trophic groups and some taxa can be well predicted with NIR (Table 1). However, some ecological indexes of nematode community structure were poorly predicted (Barthès et al., 2011). It is possible to differentiate termite species with NIR, however some factors can change the results completely (Jouquet et al., 2014). NIR was used to estimate organic matter characteristics under influence of earthworms (Hedde et al., 2013), where bulk chemistry of large macro-aggregates was changed, but SOM composition was not. 
Table 1 Wavelengths contributing heavily to NIR prediction of soil nematode groups, and chemical functions assigned to them. Adapted from (Barthès et al., 2011).

\begin{tabular}{|c|c|c|}
\hline Wavelengths & Assigned organic matter groups & Predicted nematode groups \\
\hline 1143 & Aromatic hydrocarbons & Total abundance; obligate plant feeders; omnivores; predators \\
\hline 1300 & $\mathrm{C}-\mathrm{H}$ bond & Total abundance \\
\hline 1370 & Aromatic hydrocarbons & \multirow{2}{*}{ Fungal feeders; omnivores; predators; facultative plant feeders } \\
\hline 1390 & Aliphatic hydrocarbons & \\
\hline $1460-1530$ & Amines, amides or proteins & Obligate plant feeders; omnivores; predators; facultative plant feeders \\
\hline 1570 & Amides & Obligate plant feeders; omnivores; predators \\
\hline $1680-1685$ & Aromatic hydrocarbons & Fungal feeders \\
\hline 1727 & Aliphatic hydrocarbons & \multirow{4}{*}{ Bacterial feeders; fungal feeders } \\
\hline 1735 & Amines & \\
\hline 1738 & Proteins & \\
\hline 1740 & Thiols & \\
\hline 1762 & Aliphatic hydrocarbons & \multirow{2}{*}{$\begin{array}{l}\text { Total abundance; bacterial feeders; obligate plant feeders; omnivores; } \\
\text { predators }\end{array}$} \\
\hline 1780 & Cellulose & \\
\hline 1820 & Cellulose & Bacterial feeders, fungal feeders; omnivores; predators \\
\hline $1978-1990$ & Aromatic amines, amides and proteins & $\begin{array}{l}\text { Fungal feeders; total abundance, obligate plant feeders; omnivores; } \\
\text { predators }\end{array}$ \\
\hline $2030-2070$ & Proteins or amides & Total abundance; obligate plant feeders; omnivores; predators \\
\hline 2075 & $\begin{array}{l}\text { Amides in animal ribonucleases (digestive } \\
\text { enzymes) }\end{array}$ & \\
\hline 2080 & Urea and alcohols & \multirow{3}{*}{ Total abundance, obligate plant feeders; omnivores; predators } \\
\hline 2083 & Animal proteins & \\
\hline $2090-2100$ & $\begin{array}{l}\mathrm{OH}, \mathrm{COH} \text { or } \mathrm{COOH} \text { (in polysaccharides } \\
\text { especially) }\end{array}$ & \\
\hline 2120 & Cyclic amides & \multirow{2}{*}{ Bacterial feeders } \\
\hline 2127 & Polyamides & \\
\hline $2320-2350$ & Complex sugars (e.g. cellulose) & $\begin{array}{l}\text { Total abundance; facultative plant feeders; fungal feeders; obligate plant } \\
\text { feeders }\end{array}$ \\
\hline 2363 & Aliphatic hydrocarbons & \multirow{3}{*}{ Fungal feeders } \\
\hline 2380 & Lipids & \\
\hline $2445,2463,2470$ & Proteins & \\
\hline 2458,2470 & Aliphatic hydrocarbons & \multirow{3}{*}{ Obligate plant feeders; fungal feeders; facultative plant feeders } \\
\hline 2470 & Lipids & \\
\hline 2477 & Aromatic hydrocarbons & \\
\hline
\end{tabular}

FTIR was employed in studies of branched aliphatic alkanes with quaternary substituted carbon atoms that might be nonphotosynthetic sulfide oxidizers for ancient organisms (Kenig et al., 2003). In another study microaggregates of carbon and the stabilization of carbon in the soils were investigated by FTIR (Lehmann et al., 2007). It is stated that unlike macroaggregates there is no difference in carbon distribution between exterior and interior parts of microaggregates. It is reported that the stabilization of carbon in the soils initiated mainly by accumulation of organics on clay particle surfaces, not by occlusion of organic debris by clay particles.

It should be noted that nuclear magnetic resonance (NMR), electron paramagnetic resonance (EPR) and isotope ratio mass spectrometry (IRMS) are also physical methods of analysis, but they are not covered in this review due to several reasons. First, these methods require destructive sampling and need chemical analysis, which cannot be done in situ.
Second, these methods are widely used in a laboratory, but not in the field investigation because of heavy-duty equipment restrictions.

\section{Perspective}

This review focuses on the physical methods available for the determination of soil biota and organic matter, particularly for those non-destructive methods used in the field. The selection of physical methods should be based on the suitability toward the purpose of the experiment. Although there are limitations about the physical methods, which may be highly specialized on some types of soil biota or require additional equipment such as a powerful energy source or vacuum device, the application of the following physical methods are promising.

1) Acoustical method has great potential for in situ detection of soil fauna. Soil biota can be investigated by several methods, but acoustical method is the least destructive and 
provides an opportunity to investigate soil animals in situ. It is used for studying the activity of soil animals and for mapping their populations. However, only comparatively large animals can be investigated or animals able to produce obvious sounds in their activities. The method can be improved in several ways. First way includes the collection of more soil biotic sounds, analyzing these sounds and learning to discern them. Second way is about improving the quality of recorded samples, so it involves the development of systems for noise reduction, automatic registration and identification of sound made by different soil fauna species.

2) Hyperspectral sensors are a good choice for comprehensive studies. The method may provide information about surface and sub-surface mapping of soil organic matter, roots and even soil biota. Although, techniques for the detection of the soil biota using hyperspectral sensors is still under development, soil organic matter mapping can be done nondestructively not only for surface but also subsurface soil. The method requires the increment of resolution and the miniaturization for soil biota studies.

3) Coupling of multiple methods sheds new light for soil ecology study. A number of methods can be bounded together to achieve more accurate or more comprehensive analysis. Such aforementioned methods as EDX, EELS can be combined with scanning or transmission electron microscopes due to similarity of research scales but complimentary technique, which allows simultaneous investigation of structure and chemical composition. Moreover, several methods used together could provide more detailed information and complete image about the environment or history of the soil.

\section{References}

Barthès, B.G., Brunet, D., Rabary, B., Ba, O., Villenave, C., 2011. Near infrared reflectance spectroscopy (NIRS) could be used for characterization of soil nematode community. Soil Biology \& Biochemistry 43, 1649-1659.

Bastardie, F., Capowiez, Y., Cluzeau, D., 2003. Burrowing behaviour of radio-labelled earthworms revealed by analysis of 3D-trajectories in artificial soil cores. Pedobiologia 47, 554-559.

Bauer-Reich, C., Tan, K.C., Haring, F., Schneck, N., Wick, A., Berge, L., Hoey, J., Sailer, R., Ulven, Ch., 2014. An investigation of the viability of UHF RFID for subsurface soil sensors. In: 2014 IEEE International Conference on Electro/Information Technology (EIT) IEEE, 577-580.

Birch, M.E., Bon, K.K., Evans, D., Ruda-Eberenz, T.A., 2011. Exposure and emissions monitoring during carbon nanofiber production-Part I: Elemental carbon and iron-soot aerosols. Annals of Occupational Hygiene 55, 1016-1036.

Bodner, G., Nakhforoosh, A., Arnold, T., Leitner, D., 2018. Hyperspectral imaging: a novel approach for plant root phenotyping. Plant Methods 14, 84.

Bongers, T.H., Ferris, H., 1999. Nematode community structure as a bioindicator in environmental monitoring. Trends in Ecology \& Evolution 14, 224-228.
Brandhorst-Hubbard, J.L., Flanders, K.L., Mankin, R.W., Guertal, E. A., Crocker, R.L., 2001. Mapping of soil insect infestations sampled by excavation and acoustic methods. Journal of Economic Entomology 94, 1452-1458.

Briedis, C., João, C.S., Fávero, C., Navarro, J.D.F., Inagaki, Th., Boer, A., Neto, C.Q., Ferreira, A.D.O., Canalli, L.B., Santos, J., 2012. Soil organic matter pools and carbon-protection mechanisms in aggregate classes influenced by surface liming in a no-till system. Geoderma 170, 80-88.

Brodowski, S., Amelung, W., Haumaier, L., Abetz, C., Zech, W., 2005. Morphological and chemical properties of black carbon in physical soil fractions as revealed by scanning electron microscopy and energy-dispersive X-ray spectroscopy. Geoderma 128, 116129.

Chen, J., Ferris, H., Scow, K., Graham, K., 2001. Fatty acid composition and dynamics of selected fungal-feeding nematodes and fungi. Comparative Biochemistry and Physiology. Part B, Biochemistry \& Molecular Biology 130, 135-144.

Cheng, C.H., Lehmann, J., Thies, J.E., Burton, S.D., Engelhard, M.H., 2006. Oxidation of black carbon by biotic and abiotic processes. Organic Geochemistry 37, 1477-1488.

Civiš, S., Knížek, A., Rimmer, P.B., Ferus, M., Kubelík, P., Zukalova, M., Kavan, L., Chatzitheodoridis, E., 2018. Formation of Methane and (Per)Chlorates on Mars. ACS Earth and Space Chemistry.

Coleman, D.C., Callaham, M.A., Crossley, D.A., 2016. Fundamentals of Soil Ecology. 3rd ed. Cambridge: Academic Press.

Foster, R.C., Rovira, A.D., 1976. Ultrastructure of wheat rhizosphere. New Phytologist 76, 343-352.

Garvie, L.A.J., Buseck, P.R., 2006. Carbonaceous materials in the acid residue from the Orgueil carbonaceous chondrite meteorite. Meteoritics \& Planetary Science 41, 633-642.

Haff, R.P., Saranwong, S., Thanapase, W., Janhiran, A., Kasemsumran, S., Kawano, S., 2013. Automatic image analysis and spot classification for detection of fruit fly infestation in hyperspectral images of mangoes. Postharvest Biology and Technology 86, 23 28.

Harrison, R.D., Gardner, W.A., Tollner, W.E., Kinard, D.J., 1993. X-ray computed tomography studies of the burrowing behavior of fourthinstar pecan weevil (Coleoptera: Curculionidae). Journal of Economic Entomology 86, 1714-1719.

Hedde, M., Bureau, F., Delporte, P., Cécillon, L., Decaëns, T., 2013. The effects of earthworm species on soil behaviour depend on land use. Soil Biology \& Biochemistry 65, 264-273.

Hodkinson, I.D., Jackson, J.K., 2005. Terrestrial and aquatic invertebrates as bioindicators for environmental monitoring, with particular reference to mountain ecosystems. Environmental Management 35, 649-666.

James, N., 1958. Soil extract in soil microbiology. Canadian Journal of Microbiology 4, 363-370.

Jouquet, P., Capowiez, Y., Bottinelli, N., Traoré, S., 2014. Potential of Near Infrared Reflectance Spectroscopy (NIRS) for identifying termite species. European Journal of Soil Biology 60, 49-52.

Joyner, J., Harmon, P., 1961. Burrows and oscillative behavior therein of Lumbricus terrestris. $s$ terrestris. Indiana Academy of Science 71, 378-384.

Jung, A.V., Chanudet, V., Ghanbaja, J., Lartiges, B.S., Bersillon, J.L., 
2005. Coagulation of humic substances and dissolved organic matter with a ferric salt: An electron energy loss spectroscopy investigation. Water Research 39, 3849-3862.

Kenig, F., Simons, D.J.H., Crich, D., Cowen, J.P., Ventura, G., Rehbein-Khalily, T., Brown, T.C., Anderson, K., 2003. Branched aliphatic alkanes with quaternary substituted carbon atoms in modern and ancient geologic samples. Proceedings of the National Academy of Sciences of the United States of America 100, 12554-12558.

Kokaly, R.F., Rockwell, B.W., Haire, S.L., King, T.V.V., 2007. Characterization of post-fire surface cover, soils, and burn severity at the Cerro Grande Fire, New Mexico, using hyperspectral and multispectral remote sensing. Remote Sensing of Environment 106, 305-325.

Lahaye, R., Bank, M., Bogarín, D., Warner, J., Pupulin, F., Gigot, G., Maurin, O., Duthoit, S., Barraclough, T., Savolainen, V., 2008. DNA barcoding the floras of biodiversity hotspots. Proceedings of the National Academy of Sciences of the United States of America 105, 2923-2928.

Lawrence, A.P., Bowers, M.A., 2002. A test of the "hot" mustard extraction method of sampling earthworms. Soil Biology \& Biochemistry 34, 549-552.

Lehmann, J., Kinyangi, J., Solomon, D., 2007. Organic matter stabilization in soil microaggregates: implications from spatial heterogeneity of organic carbon contents and carbon forms. Biogeochemistry 85, 45-57.

Li, Z., Guo, X., 2018. Non-photosynthetic vegetation biomass estimation in semiarid canadian mixed grasslands using ground hyperspectral data, Landsat $8 \mathrm{OLI}$, and Sentinel-2 images. International Journal of Remote Sensing 39, 1-21.

Liang, B., Lehmann, J., Solomon, D., Sohi, S., Thies, J., Skjemstad, J. O., Luizão, F., Engelhard, M., Neves, E., Wirick, S., 2008. Stability of biomass-derived black carbon in soils. Geochimica et Cosmochimica Acta 72, 6069-6078.

Lins, U., Barros, C.F., da Cunha, M., Miguens, F.C., 2002. Structure, morphology, and composition of silicon biocomposites in the palm tree Syagrus coronata (Mart.) Becc. Protoplasma 220, 89-96.

Mankin, R.W., Brandhorst-Hubbard, J.L., Flanders, K.L., Zhang, M., Crocker, R.L., Lapointe, S.L., McCoy, C.W., Fisher, J.R., Weaver, D.K., 2000. Eavesdropping on insects hidden in soil and interior structures of plants. Journal of Economic Entomology 93, 1173 1182.

Mankin, R.W., Crocker, R.L., Flanders, K.L., Shapiro, J.P., 1998. Acoustic detection and identification of insects in soil. In: Kuhl, P. K., Crum, L.A. (eds.), Proceedings of the 16th International Congress of Acoustics and the 135th Annual Meeting of the Acoustical Society of America, 685-686.

Mankin, R.W., Sun, J.S., Shuman, D., Weaver, D.K., 1997. Shielding against noise interfering with quantitation of insect infestations by acoustic detection systems in grain elevators. Applied Acoustics 50, 309-323.

Narvankar, D.S., Singh, C.B., Jayas, D.S., White, N.D.G., 2009. Assessment of soft X-ray imaging for detection of fungal infection in wheat. Biosystems Engineering 103, 49-56.

Njoroge, A.W., Mankin, R.W., Smith, B.W., Baributsa, D., 2017. Effects of hermetic storage on adult Sitophilus oryzae L. (coleoptera: Curculionidae) acoustic activity patterns and mortality. Journal of Economic Entomology 110, 2707-2715.

Njoroge, A.W., Mankin, R.W., Smith, B.W., Baributsa, D., 2018. Oxygen consumption and acoustic activity of adult Callosobruchus maculatus (F.) (coleoptera: Chrysomelidae: Bruchinae) during hermetic storage. Insects 9, 45.

Raw, F., 1959. Estimating earthworm populations by using formalin. Nature 184, 1661-1662.

Raw, F., 1960. Earthworm population studies: a comparison of sampling methods. Nature 187, 257-257.

Scheibler, E., Roschlau, C., Brodbeck, D., 2014. Lunar and temperature effects on activity of free-living desert hamsters (Phodopus roborovskii, Satunin 1903). International Journal of Biometeorology 58, 1769-1778.

Schmidt, O., 2001a. Time-limited soil sorting for long-term monitoring of earthworm populations. Pedobiologia 45, 69-83.

Schmidt, O., 2001b. Appraisal of the electrical octet method for estimating earthworm populations in arable land. Annals of Applied Biology 138, 231-241.

Singh, C., Jayas, D., Paliwal, J., White, N., 2010. Identification of insect-damaged wheat kernels using short-wave near-infrared hyperspectral and digital colour imaging. Computers and Electronics in Agriculture 73, 118-125.

Skinner, F.A., Jones, P.C.T., Mollison, J.E., 1952. A Comparison of a direct- and a plate-counting technique for the quantitative estimation of soil micro-organisms. Journal of General Microbiology 6, 261-271.

Sogin, M., Morrison, H., Huber, J., Welch, D., Huse, S., Neal, P., Arrieta, J., Herndl, G., 2006. Microbial diversity in the deep sea and the underexplored "rare biosphere". Proceedings of the National Academy of Sciences of the United States of America 103, 1211512120.

Taylor, J., 1962. The estimation of numbers of bacteria by tenfold dilution series. Journal of Applied Bacteriology 25, 54-61.

Tisdall, J.M., McKenzie, B.M., 1999. A method of extracting earthworms from cores of soil with minimum damage to the soil. Biology and Fertility of Soils 30, 96-99.

Wang, X., Zhang, F., Kung, H., Johnson, V., 2018. New methods for improving the remote sensing estimation of soil organic matter content (SOMC) in the Ebinur Lake Wetland National Nature Reserve (ELWNNR) in northwest China. Remote Sensing of Environment 218, 104-118.

Wetterlind, J., Stenberg, B., Söderström, M., 2010. Increased sample point density in farm soil mapping by local calibration of visible and near infrared prediction models. Geoderma 156, 152-160.

Wheater, C.P., Bell, J.R., Cook P.A., 2011. Practical Field Ecology: A Project Guide. Wiley-Blackwell, 109.

Zhu, G., Petersen, M.J., Liu, G., Peck, D.C., 2013. Imidacloprid as a contact arrestant for larvae of the european chafer, amphimallon majale. Pest Management Science 69, 483-492. 